\title{
H-FABP in Pre Capillary Pulmonary Hypertension: Comparison to Other Surrogate Parameters for Prediction of Severity and Outcome
}

\author{
Hagen Schroetter ${ }^{1}$, Michael Halank ${ }^{2}$, Dirk Stolte ${ }^{1}$, Peggy Barthel ${ }^{1}$, Gert Hoeffken ${ }^{2}$, \\ Ruediger C. Braun-Dulleaus ${ }^{3}$, Ruth H. Strasser ${ }^{1}$, Alexander Schmeisser ${ }^{3}$ \\ ${ }^{1}$ University of Technology Dresden, Medical Clinic and Cardiology, Heart Center Dresden, \\ University Hospital, Germany \\ ${ }^{2}$ University of Technology Dresden, Medical Clinic/Pneumology, University Hospital, Germany \\ ${ }^{3}$ Otto-von-Guericke University Magdeburg, Medical Clinic/Cardiology, Pneumology and Angiology, Germany \\ E-mail: hagen.schroetter@mailbox.tu-dresden.de \\ Received August 8, 2011; revised August 19, 2011; accepted August 23, 2011
}

\begin{abstract}
Background: Heart-type fatty acid-binding protein (H-FABP) is a promising novel biomarker for risk stratification of patients with chronic thromboembolic pulmonary hypertension (CTEPH). Whether disease severity in a group of patients with pre capillary pulmonary hypertension $(\mathrm{PH})$ can be predicted by determination of plasma H-FABP levels remains unknown. Methods: 41 consecutive patients with a mean $( \pm \mathrm{SD})$ age of $60.6 \pm 2.1$ years and severe PH were studied with a mean follow up to 541 days (95\% CI: 420; 661 days). H-FABP, but also the biomarkers NT-Pro-BNP and big-endothelin (Big-ET1), were correlated to parameters derived from right sided cardiac catheterization and cardio-pulmonary exercise test. Results: At baseline H-FABP levels ranged from 620 to $15200 \mathrm{pg} / \mathrm{ml}(3648 \pm 502 \mathrm{pg} / \mathrm{ml})$ and were weakly but significantly correlated to $\mathrm{VO}_{2} \mathrm{AT}(\mathrm{r}=-0.37, \mathrm{p}=0.04)$ and $\mathrm{VO}_{2}$ peak $(\mathrm{r}=-0.38, \mathrm{p}=0.03)$. However, invasively measured hemodynamic parameters of $\mathrm{PH}$ and right ventricular dysfunction did not correlate with H-FABP levels. Interestingly, moderate to high correlations between H-FABP and NT-Pro-BNP $(\mathrm{r}=0.51, \mathrm{p}=0.01)$ and Big-ET1 $(r=0.65, p=0.01)$ and between Big-ET1 and NT-Pro-BNP $(r=0.5, p=0.01)$ could be observed. In contrast to H-FABP, NT-Pro-BNP, and even more Big-ET1, showed significant correlations to different invasively measured hemodynamic parameters of the disease indicating severity and consequently prognosis of severe pre-capillary pulmonary hypertension. However, in a multivariate Cox regression analysis, PVR, mixed venous oxygen saturation and the $\mathrm{VE} / \mathrm{VCO}_{2}$ slope $(>60)$ as well as the heart rate recovery within one minute (HRR) but none of the biomarkers were identified as independent factors of poor prognosis. In contrast, peak workload and mixed venous saturation were identified as risk markers in the idiopathic pulmonary arterial hypertension subgroup. Conclusions: In contrast to the predictive value of H-FABP in CTEPH $\mathrm{H}-\mathrm{FABP}$ fails to be a reliable marker in $\mathrm{PH}$ or to be a novel predictor of mid and long term outcome. The data suggest that an increased slope of $\mathrm{VE} / \mathrm{VCO}_{2}$ and a decreased extent of $\mathrm{HRR}$ within one minute represent more promising diagnostic non invasive parameters.
\end{abstract}

Keywords: Human Fatty Acid Binding Protein, Biomarker, Pulmonary Hypertension, Prognosis

\section{Introduction}

Pulmonary arterial hypertension $(\mathrm{PAH})$ is a progressive disease with poor prognosis due to fatal right heart failure. The accurate assessment of prognosis in these patients is difficult. Moreover, the optimal timing for com- bining medical therapy or planning invasive procedures such as atrial septostomy or lung transplantation remains controversial [1]. Worsening of invasively determined hemodynamic indices of right ventricular dysfunction, a poor functional status, or a low distance in 6 minute walk test (6MWT) [2-4] may be indicative of severity and 
prognosis of pulmonary hypertension. The estimate of right ventricular systolic pressure derived from Doppler sonography is helpful to screen patients with PH but was found not to be predictive for outcome [5,6]. A variety of atrial, ventricular, and Doppler parameters were suggested to be associated with an increased risk of death or need for transplantation in patients with PAH $[7,8]$. However, the drawback of Doppler sonography is its operator-dependency. Therefore, simple, non invasive, easily accessible and quantitative parameters which are repeatedly available and possibly quantitative methods to detect PH patients are still needed. Such parameters are of utmost value for follow up during therapy. Cardiac biomarkers in plasma such as plasma brain natriuretic peptide (BNP) or the N-terminal part of its pro-hormone (NT-pro-BNP) appear to have promising potential [9] [10]. Thus, it has been demonstrated that plasma BNP levels increase in correlation with the degree of right ventricular (RV) dysfunction and are well predictive for the functional status of patients with idiopathic pulmonary hypertension (IPAH) [11,12]. Consequently, high levels of BNP at baseline, and in particular, a further rise in plasma BNP during follow up of 3 months are independent prognostic factors in these patients [13]. NTpro-BNP could be related with cardiopulmonary hemodynamics in patients with idiopathic PAH and with poor long term prognosis in an unselected patient population with pre-capillary PH [14]. Recently, other heart biomarkers reflecting myocardial injury, such as troponin or H-FABP gained increasing interest. Fatty acid-binding proteins (FABPs) are relatively small $(15 \mathrm{KDa})$ cytosolic proteins that are widely distributed and highly expressed in tissues undergoing active fatty-acid metabolism, such as the heart and the liver [15]. The H-FABP (heart-type fatty acid-binding protein) isoform is one of the most abundant proteins in myocardial tissue, representing $5 \%$ $15 \%$ of the whole aqueous cytosolic protein pool of the heart. H-FABP is truly cytosolic and has not been found outside the cell or in plasma under normal conditions [16]. The fact that H-FABP is a small protein, allows rapid diffusion and release from the injured myocardium resulting in a rapid increase in the plasma which suggests the H-FABP may be a valuable and easily accessible biomarker. This has qualified H-FABP as a rapid marker for example in myocardial infarction [17]. Therefore, it is conceivable that H-FABP may also be a reliable biomarker in other cardiac diseases with myocardial damage such as pulmonary hypertension or acute pulmonary embolism (PE). In fact, Puls et al. [18] and Kaczynsky et al. [19] identified H-FABP as an early, highly sensitive and specific indicator of death or serious complications in acute PE. Moreover, recently, Lankeit et al. [20] assessed the prognostic value of this biomarker in a large, single center population of 93 consecutive patients with CTEPH. The results indicate that H-FABP is more sensitive than cardiac troponins in predicting an adverse outcome in these settings. But, the prognostic value of H-FABP was not compared to that of BNP and NTPro-BNP, which are commonly used as biomarkers in pulmonary hypertension [21]. Moreover, it is unknown whether H-FABP is a parameter that can be applied as a prognostic marker not only in CTEPH patients but also in patients with chronic pulmonary artery hypertension (PH) due to various diseases.

Therefore, in the present study, we addressed the question if H-FABP may be used as a prognostic indicator and marker for the severity of the disease with various forms of chronic pre-capillary PH. Therefore patients with different disease stages and on different therapeutic regimens were investigated. In addition, the predictive value of H-FABP was compared with other well established biomarkers such as NT-pro-BNP, invasive hemodynamic measures and the exercise tests CPET and 6 MWT in this patient group.

\section{Materials and Methods}

\subsection{Inclusion and Exclusion Criteria}

41 consecutive patients (18 male, 23 female), referred for invasive hemodynamic evaluation for chronic pre-capillary PH from June 2004 to February 2007, were evaluated. According to the revised classification of $\mathrm{PH}, 27$ patients had pulmonary arterial hypertension (PAH), 23 IPAH and 4 were associated with systemic sclerosis. In addition, 8 patients had angiographically verified chronic thromboembolic PH (CTEPH), 5 patients interstitial lung disease associated pulmonary hypertension [sarcoidosis associated fibrosis $(\mathrm{n}=1)$, connective tissue disease $(\mathrm{n}=$ $2)$, idiopathic pulmonary fibrosis $(n=2)$ and 1 patient was in the miscellaneous group diagnosed as having sarcoidosis without fibrosis associated pulmonary hypertension]. At baseline examination, 13 patients were treated with bosentan alone, 6 with sildenafil and 2 patients with both (Table 1). At the follow up visit, all but 2 patients were medicated with the endothelin receptor antagonists or sildenafil. In 2 patients, a combination therapy was initiated. In 2 patients a specific therapy could not be initiated due to various contra-indications, lack of compliance, or multimorbidity with a very short expected life time.

Exclusion criteria were: Patients with pulmonary hypertension due to congestive left heart failure, hypertrophic or restrictive cardiomyopathy or caused by severe left sided valvular heart diseases, patients with life limiting severe concomitant diseases such as malignant neo- 
Table 1. Hemodynamic, biomarker and CPET baseline characteristics of 41 patients with pre-capillary pulmonary hypertension of different cause regarding of adverse and not adverse outcome (medications: numbers within parenthesis indicates medication before baseline examination and outside the parenthesis after the examination); ETBR = endothelin receptor blockers.

\begin{tabular}{|c|c|c|c|c|c|}
\hline Variable & & All patients $n=41$ & Adverses outcome $n=9$ & No adverse outcome $n=32$ & $p$ value \\
\hline Female & $\mathrm{n}$ & 23 & 3 & 20 & \\
\hline Age (years) & years & $60.6 \pm 2.1$ & $59.0 \pm 3.8$ & $61.0 \pm 2.5$ & 0.67 \\
\hline $6 \mathrm{MWT}$ & $\mathrm{m}$ & $282 \pm 26$ & $277 \pm 21$ & $283 \pm 31$ & 0.88 \\
\hline $\mathrm{VO}_{2}$ peak & $\mathrm{ml} / \mathrm{kg} * \min$ & $11.7 \pm 0.6$ & $11.5 \pm 0.5$ & $11.7 \pm 0.7$ & 0.81 \\
\hline Work load max & Watt & $57 \pm 4$ & $50 \pm 4$ & $59 \pm 4$ & 0.09 \\
\hline $\mathrm{VE} / \mathrm{VCO}_{2}$ Slope & & $55.2 \pm 2.5$ & $62.5 \pm 4.9$ & $53.1 \pm 2.8$ & 0.12 \\
\hline Heart rate recovery & bpm & $10.4 \pm 0.8$ & $5.7 \pm 0.6$ & $11.5 \pm 0.9$ & 0.004 \\
\hline Bosentan/Sitaxentan & & 11 & 5 & 6 & \\
\hline Sildenafil & & 8 & 2 & 6 & \\
\hline \multicolumn{6}{|l|}{ Hemodynamics } \\
\hline PAmean & $\mathrm{mmHg}$ & $50.2 \pm 1.9$ & $46.0 \pm 1.9$ & $51.4 \pm 2.4$ & 0.24 \\
\hline PCWP & $\mathrm{mmHg}$ & $7.7 \pm 1.0$ & $5.8 \pm 2.0$ & $8.3 \pm 1.2$ & 0.3 \\
\hline TPG & $\mathrm{mmHg}$ & $42.6 \pm 2.0$ & $40.2 \pm 2.0$ & $43.4 \pm 2.4$ & 0.51 \\
\hline RAP & $\mathrm{mmHg}$ & $8.8 \pm 0.9$ & $8.0 \pm 2.8$ & $9.1 \pm 0.9$ & 0.63 \\
\hline RVEDP & $\mathrm{mmHg}$ & $13 \pm 2$ & $13 \pm 1$ & $13 \pm 3$ & 0.93 \\
\hline $\mathrm{SaO}_{2}$ & $\%$ & $90 \pm 2$ & $91 \pm 2$ & $88 \pm 2$ & 0.55 \\
\hline $\mathrm{SvO}_{2}$ & $\%$ & $55 \pm 2$ & $55 \pm 2$ & $54 \pm 3$ & 0.87 \\
\hline $\mathrm{CO}$ & $1 / \min$ & $3.7 \pm 0.2$ & $3.7 \pm 0.5$ & $3.7 \pm 0.2$ & 0.99 \\
\hline PVR & dyn*s*cm ${ }^{-5}$ & $1029 \pm 91$ & $1006 \pm 78$ & $1036 \pm 117$ & 0.83 \\
\hline \multicolumn{6}{|l|}{ Biomarker } \\
\hline NTpro-BNP & $\mathrm{fmol} / \mathrm{ml}$ & $1711 \pm 198$ & $1258 \pm 242$ & $1870 \pm 248$ & 0.18 \\
\hline Big-ET & $\mathrm{fmol} / \mathrm{ml}$ & $0.84 \pm 0.13$ & $1.04 \pm 0.41$ & $0.79 \pm 0.12$ & 0.58 \\
\hline H-FABP & $\mathrm{pg} / \mathrm{ml}$ & $3648 \pm 502$ & $4004 \pm 1202$ & $3548 \pm 557$ & 0.71 \\
\hline
\end{tabular}

plasms, pregnancy or juvenile patients $(<18$ years). All patients were informed and signed the written informed consent. The study was approved by the local ethic committee.

\subsection{Six Minute Walk Test (6-MWT), Cardiopulmonary Exercise Test (CPET) and Hemodynamic Evaluation}

For evaluation of endurance, all patients performed a 6-MWT according to the American Thoracic Society guidelines [22] at first. All patients underwent a cardio- pulmonary exercise test (using the incremental cycling test method, upright cycle ergometer, ramp rate 5 to 15 watts per min, Schiller co., Germany). Transnasal respiration was avoided using a nose clip resulting in inspiration of room air via a mouthpiece with a two way valve. Standard 12 channel ECG tracings were monitored at rest, at one minute intervals and during the exercise and the recovery period. After an adoption period of 3 minutes of unloaded cycling, patients cycled under an increasing load until a symptom-limited maximum was attained. Various parameters were measured continuously. Heart rate, systolic and diastolic blood pressure, respiratory 
minute volume (VE in litre), ventilatory oxygen uptake $\left(\mathrm{VO}_{2}\right)$ at anaerobic threshold (AT) and at exertion maximum (peak), respiratory carbon dioxide delivery $\left(\mathrm{VCO}_{2}\right)$ and calculated data such as respiratory quotient (RQ); respiratory efficacy $\left(\mathrm{VCO}_{2} \mathrm{Slope}\right)$, the oxygen pulse at anaerobic threshold, and peak load $\left(\mathrm{O}_{2} \mathrm{HRAT}, \mathrm{O}_{2} \mathrm{HR}\right.$ peak in $\mathrm{ml}$ ) were monitored. Within 24 to 48 hours after CPET/6MWT the diagnostic right heart catheterization was performed while patients were in stable condition during hospitalization. Baseline hemodynamic variables including mean pulmonary arterial pressure (MPAP), mean right atrial pressure (RAP), pulmonary capillary wedge pressure (PCWP), and RV end-diastolic pressure (RVEDP) were measured. Cardiac output (CO) was measured by Fick's method. Total pulmonary resistance (PVR) was calculated by dividing mean pulmonary arterial pressure by cardiac output, the resistance index (RI) was calculated by the ratio of PVR and SVR.

\subsection{Biomarker Testing}

Central venous blood samples were collected at the time of the initial right heart diagnostic catheter. Samples were immediately stored at $-80^{\circ} \mathrm{C}$ until analysis ensuring a single thaw for all consecutive samples from a single patient.

Human-FABP was measured in serum using an ELISA Test Kit based on the sandwich principle (HyCult Biotechnology, Uden the Nederlands). The minimum detection level for H-FABP was $250 \mathrm{pg} / \mathrm{ml}$ with measurable concentrations up to $25.000 \mathrm{pg} / \mathrm{ml}$. Serum NTPro-BNP was determined, as well (Enzyme immunoassay, Biomedica, Austria). The minimum detection level was $5 \mathrm{fmol} / \mathrm{ml}$ at $95 \% \mathrm{~B} / \mathrm{Bo}$. The absorbance was measured at $450 \mathrm{~nm}$. Big endothelin (BigET1) was measured by an enzyme immunoassay for the quantitative determination of human big endothelin in EDTA plasma. The detection limit was $0.025-0.05 \mathrm{fmol} / \mathrm{ml}$ and reached a range between $0.025-25 \mathrm{fmol} / \mathrm{ml}$. The cross reactivity with ET1/2/3 and Big-ET2 is $<1 \%$ (Enzyme immunoassay, Biomedica, Austria, www.bmgrp.com). The investtigator who quantified the biomarker levels was blinded for hemodynamic parameters of the patient or the clinical course. Biomarker levels were not used to guide patient management or to monitor the effects of treatment during the initial hospital stay or at any time during the follow up period.

\subsection{Survival Estimates}

Survival was estimated from the date of blood sampling to March, 31, 2008, or cardiopulmonary death or lung transplantation with a follow up rate of $100 \%$.

\subsection{Statistical Analysis}

Based on the test result of equal distribution by the Kolmogorow-Smirnow test, the baseline characteristics of survivors and non survivors were compared with the execution of the two-sided t-test for all continuous, metric scaled variables. All data were described by arithmetic mean \pm SEM. Bivariate correlations between metric scaled groups were recorded by Pearson's coefficient $r$. The Spearman rank correlation (rho) test was performed, if at least one of the variables was non parametric. A coefficient value between 0.2 and 0.5 [-0.2 and -0.5$]$, respectively, was regarded as a weak, a $\mathrm{r}$ or rho between 0.5 and 0.7 ( -0.5 and -0.7 respectively) as a moderate correlation.

At march 31, 2008 data of vital status or date of death from any cause or heart-lung transplantation (HLTx), the combined end point, were assessed. Event (or censoring) times for all patients were measured from the time of study inclusion (time zero). All patients were evaluated at the end of the follow up. To estimate the correlation of biomarkers to survival, differences between groups with normal or low marker levels vs. elevated marker levels were determined by the log-rank statistic and the time to the end point plotted according to Kaplan-Meier method. First, all hazard ratios for death or HLTx were measured unadjusted for covariates, followed by the use of Cox proportional regression models for survival adjustment for age, gender, specific pulmonary vasoreactive medication at baseline or specific therapy extension during the follow up period. Hazard ratios were reported with their associated 95\% confidence interval. Hazard ratios were illustrated by Forest plots graphs. For all test results we considered a two tailed $\mathrm{p} \leq 0.05$ significant.

Statistical analysis was performed with SPSS for Windows, release 11.5.

\section{Results}

During a mean follow up period of 541 days (95\% CI 420 ; 661$) 9$ of 41 consecutive patients $(22 \%)$ died of cardiopulmonary cause or underwent lung transplantation $(n=4)$. Most of the patients who died $(n=6,15 \%)$ died in the first year after the baseline visit. (Figure 1). Thereafter, the Kaplan-Meier survival curve levelled off for the rest of the observation period.

\subsection{Comparison of Characteristics of All Patients with Pre-Capillary Pulmonary Hypertension}

At baseline, the characteristics of the patients with adverse outcome compared to those without adverse out- 


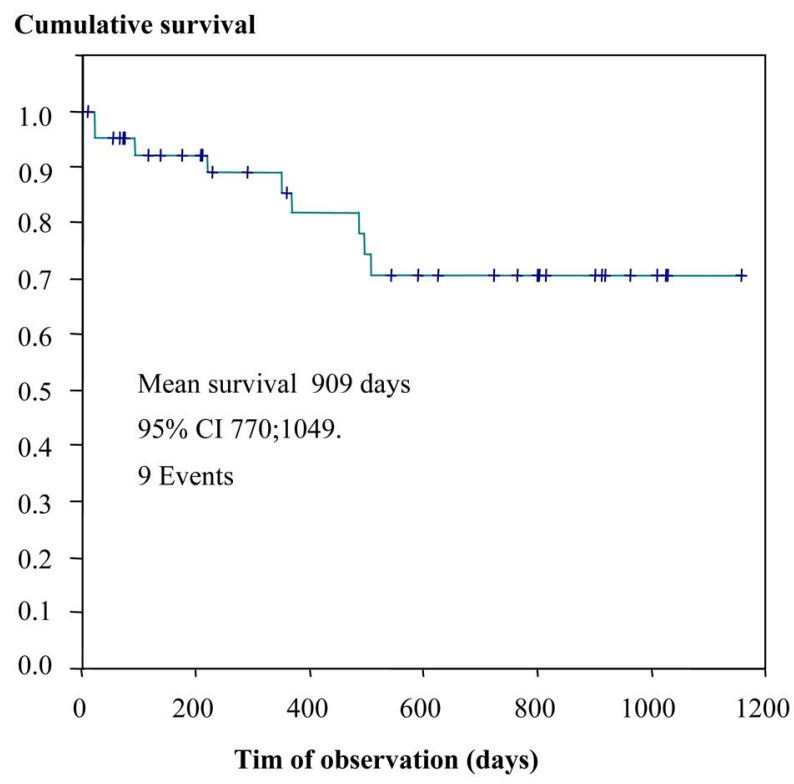

Figure 1. Kaplan-Meier survival curve in PH patients. The graph represents the survival with a maximum observation time of 1159 days.

come did not differ significantly. Also there was no significant difference in the use of medications. At baseline, neither the distance of the 6 minute walk test, $\mathrm{VO}_{2}$ peak, $\mathrm{VE} / \mathrm{VECO}_{2}$ Slope nor RA mean, the PVR or cardiac output were able to discriminate between the two groups (Table 1). Moreover, no difference was found in the serum levels of the biomarkers NT-pro BNP, Big-ET and H-FABP. Only the heart rate recovery within the first minute after stress test was significantly delayed in patients with adverse outcome compared to patients without adverse outcome $(5.7 \pm 0.6 \mathrm{bpm}$ vs. $11.5 \pm 0.9 \mathrm{bpm}$, $\mathrm{p}=0.004$; Table 1). The maximal work load showed only a trend toward lower values in patients with adverse outcome $(\mathrm{p}=0.09)$.

Comparison of characteristics of the selected IPAH group of patients with adverse and without adverse outcome In the group of 23 IPAH patients 6 patients died (26\%) of cardiopulmonary causes, and four patients underwent a lung transplantation during the follow up period. Patients with no adverse outcome had faster heart rate recovery within the first minute after stress test $(11 \pm$ 1 vs. $5.6 \pm 0.7 \mathrm{bpm}, \mathrm{p}=0.01)$ and reached a higher maximal work load ( $63 \pm 0.5$ vs. $45 \pm 3$ Watt, $p=0.01)$. In right heart catheter survivors had a PCWP within the normal range but significantly higher than patients with an adverse outcome ( $8 \pm 1$ vs. $3 \pm 1 \mathrm{mmHg}, \mathrm{p}=0.04)$. The arterial oxygen saturation was significantly higher in the survivor group, too (92 \pm 1 vs. $87 \pm 1 \%, \mathrm{p}=0.03$ ) (Table 2). Also in IPAH patients, $\mathrm{VO}_{2}$ peak, VE/ $/ \mathrm{VECO}_{2}$ slope, RAP, PVR or cardiac output failed to discriminate between those with or without adverse outcome. Simi- larly, the serum levels of the biomarkers NT-pro BNP, Big-ET and H-FABP could not indicate the risk of patients for worsening right heart failure or death (Table 2).

\subsection{Correlation of the H-FABP with Exercise (CPET), Hemodynamic Parameters and with Other Biomarkers (NT-Pro BNP, Big-ET) in All Patients with Pre-Capillary PH}

\subsubsection{CPET}

At baseline evaluation, H-FABP levels in plasma ranged from 620 to $15200 \mathrm{pg} / \mathrm{ml}(3648 \pm 502 \mathrm{pg} / \mathrm{ml})$ and were weakly correlated with $\mathrm{VO}_{2} \mathrm{AT}(\mathrm{r}=-0.37, \mathrm{p}=0.04)$ and $\mathrm{VO}_{2}$ peak $(\mathrm{r}=-0.38, \mathrm{p}=0.03)($ Table 3(a)).

\subsubsection{Hemodynamic Parameters}

Plasma H-FABP levels did not correlate with invasively measured hemodynamic parameters of pulmonary hypertension and right ventricular dysfunction. (Table 3(b)).

\subsection{Bivariate Correlation of H-FABP with the Biomarkers NT-Pro-BNP and Big-ET1}

At the time of baseline evaluation, mean NT-Pro-BNP levels were $1711 \pm 198 \mathrm{fmol} / \mathrm{ml}$ and Big-ET $0.84 \pm 0.13$ $\mathrm{fmol} / \mathrm{ml}$ (Table 1). Interestingly, we observed a moderate correlation between H-FABP and NT-Pro-BNP $(r=$ $0.51, \mathrm{p}=0.01)$. The correlation between H-FABP and Big-ET was even closer $(r=0.65, p=0.01)$. Big-ET and NT-Pro-BNP were moderately associated with each another $(\mathrm{r}=0.5, \mathrm{p}=0.01$; Table 3(a)). Like H-FABP, BigET and NT-Pro-BNP correlated weakly with $\mathrm{VO}_{2}$ peak $(\mathrm{r}$ $=-0.39, \mathrm{p}=0.02$ and $\mathrm{r}=-0.45, \mathrm{p}=0.03$, respectively). But in contrast to H-FABP, NT-Pro-BNP, and even more Big-ET, showed significant correlations to invasively measured hemodynamic parameters with known prognostic significance (NT-Pro-BNP: RAP: $\mathrm{r}=48, \mathrm{p}=0.02$, mixed venous saturation $\left(\mathrm{SVO}_{2}\right) \mathrm{r}=-0.64, \mathrm{p}=<0.001$; (Big-ET: MPAP: $\mathrm{r}=0.41, \mathrm{p}=0.04$; RI $\mathrm{r}=0.53, \mathrm{p}=$ $0.004 ; \mathrm{SVO}_{2}: \mathrm{r}=-0.53, \mathrm{p}=0.002$; RVEDP: $\mathrm{r}=0.53, \mathrm{p}=$ 0.001 and RAP: $r=0.73, p=0.001$ ).

\subsection{Risk Estimates for Adverse Outcome}

\subsubsection{H-FABP in Comparison to NT-Pro-BNP and Big-ET}

The impact of these biomarkers on observed outcome was assessed by Kaplan-Meier Analysis according to median values of baseline. No relevant cut off values for a significant prediction of death or transplantation were identified by ROC analysis of the analysed biomarkers. 
Table 2. Hemodynamic, biomarker and CPET baseline characteristics of 23 patients with IPAH regarding of adverse and not adverse outcome (medications: numbers within parenthesis indicates medication before baseline examination and outside the parenthesis after the examination).

\begin{tabular}{|c|c|c|c|c|c|}
\hline \multicolumn{6}{|c|}{ Subgroup of IPAH patients $(\mathrm{n}=23)$} \\
\hline Variable & & IPAH patients $n=23$ & Adverses outcome $n=6$ & No adverse outcome $n=17$ & $p$ value \\
\hline Gender female & & 13 & 2 & 11 & \\
\hline Age (years) & years & $61.3 \pm 2.5$ & $55.8 \pm 5.0$ & $63.1 \pm 2.9$ & 0.22 \\
\hline $6 \mathrm{MWT}$ & $\mathrm{m}$ & $319 \pm 27$ & $298 \pm 8$ & $323 \pm 30$ & 0.73 \\
\hline $\mathrm{VO}_{2}$ peak & $\mathrm{ml} / \mathrm{kg}^{*} \min$ & $12.0 \pm 0.8$ & $11.0 \pm 0.5$ & $12.3 \pm 1.0$ & 0.24 \\
\hline Work load max. & Watt & $59 \pm 5$ & $45 \pm 3$ & $63 \pm 5$ & 0.01 \\
\hline $\mathrm{VE} / \mathrm{VCO}_{2}$ Slope & & $56.7 \pm 3.3$ & $66.7 \pm 2.6$ & $53.9 \pm 5.0$ & 0.12 \\
\hline Heart rate recovery & bpm & $9.8 \pm 1.0$ & $5.6 \pm 0.7$ & $11 \pm 1.0$ & 0.01 \\
\hline Bosentan/Sitaxentan & & 7 & 3 & 4 & \\
\hline Sildenafil & & 4 & 2 & 2 & \\
\hline \multicolumn{6}{|l|}{ Hemodynamics } \\
\hline PAmean & $\mathrm{mmHg}$ & $48 \pm 2$ & $46 \pm 2$ & $49 \pm 3$ & 0.5 \\
\hline PCWP & $\mathrm{mmHg}$ & $7 \pm 1$ & $3 \pm 1$ & $8 \pm 1$ & 0.04 \\
\hline TPG & $\mathrm{mmHg}$ & $42 \pm 2$ & $43 \pm 2$ & $41 \pm 3$ & 0.69 \\
\hline RAP & $\mathrm{mmHg}$ & $7 \pm 1$ & $5 \pm 2$ & $8 \pm 1$ & 0.18 \\
\hline RVEDP & $\mathrm{mmHg}$ & $12 \pm 2$ & $10 \pm 3$ & $13 \pm 2$ & 0.34 \\
\hline $\mathrm{SaO}_{2}$ & $\%$ & $91 \pm 1$ & $87 \pm 1$ & $92 \pm 1$ & 0.03 \\
\hline $\mathrm{SvO}_{2}$ & $\%$ & $57 \pm 2$ & $54 \pm 3$ & $58 \pm 2$ & 0.38 \\
\hline $\mathrm{CO}$ & $1 / \min$ & $3.7 \pm 0.2$ & $3.3 \pm 0.2$ & $3.8 \pm 0.3$ & 0.16 \\
\hline PVR & dyn*s*cm ${ }^{-5}$ & $998 \pm 91$ & $1058 \pm 73$ & $977 \pm 122$ & 0.7 \\
\hline \multicolumn{6}{|l|}{ Biomarker } \\
\hline NTpro-BNP & $\mathrm{fmol} / \mathrm{ml}$ & $1667 \pm 245$ & $1272 \pm 339$ & $1799 \pm 304$ & 0.21 \\
\hline Big-ET & $\mathrm{fmol} / \mathrm{ml}$ & $0.67 \pm 0.14$ & $0.84 \pm 0.49$ & $0.61 \pm 0.12$ & 0.84 \\
\hline H-FABP & $\mathrm{pg} / \mathrm{ml}$ & $3010 \pm 536$ & $3259 \pm 975$ & $2928 \pm 492$ & 0.34 \\
\hline
\end{tabular}

(Figure 2, Kaplan Meyer curve for NTproBNP not shown). The multivariate, logistic forward stepwise Cox regression analysis with death or HLTx as dependent factors was adjusted for age, gender, specific pulmonary vasoreactive medication at baseline or specific therapy extension during the follow up period. Neither in unselected patients with pre-capillary $\mathrm{PH}$ nor in the IPAH group, plasma H-FABP demonstrated a significant predictive value for an adverse outcome (HR of 1,0 for an increase by $1 \mathrm{pg} / \mathrm{ml} ; 95 \% \mathrm{CI} 0,99 ; 1,01)$. Surprisingly, nearly the same results were obtained after analysis of NT-Pro-BNP in the unselected group but also in the
IPAH group (Table 4). Only Big-ET showed a trend for a positive prediction of an adverse outcome for each increase of BigET1 by $1 \mathrm{fmol} / \mathrm{ml}$ (all patients: HR 1.88 (0.89 - 3.97), $\mathrm{p}=0.09$; IPAH: HR 5.01 (0.65 - 38.71), $\mathrm{p}$ $=0.12)$.

\subsubsection{Outcome Estimates Based on Hemodynamic and Exercise Tested Variables: Multivariate Predictive Analysis}

In the multivariate Hazard ratio proportional test for hemodynamic factors of pulmonary hypertension and/or right ventricular dysfunction, only a PVR over 900 dyn*s* 
Table 3. Bivariate correlation of HFABP, Big-ET and BT-Pro-BNP with exercise parameters (CPET) (a) and invasive measured parameters of pulmonary hypertension and right ventricular dysfunction (b) in 41 patients with pre-capillary pulmonary hypertension. $\mathrm{VO}_{2}=$ Oxygen consumption; AT $=$ aerob/anaerob threshold; peak= maximum of exertion; $6 \mathrm{MWD}=6$ minute walk distance. MAP = mean arterial pressure; MPAP mean pulmonary artery pressure; PCWP = pulmonary capillary wedge pressure; $T P G=$ trans pulmonary pressure gradient; $m R A P=$ mean right atrial pressure; $R V E D P=$ right end-diastolic filling pressure; PVR = pulmonary vascular resistance, SVR: systemic vascular resistance).

(a)

\begin{tabular}{|c|c|c|c|c|c|c|c|}
\hline \multicolumn{8}{|c|}{ Bivariate correlation of CPET and biomarkers at baseline } \\
\hline Parameter & Unit & H-FABP & $\mathbf{p}$ & BNP & $\mathbf{p}$ & BigET1 & $\mathbf{p}$ \\
\hline $\mathrm{VO}_{2} \mathrm{AT}$ & $\mathrm{ml} / \mathrm{min} * \mathrm{~kg}$ & -0.37 & 0.04 & -0.21 & 0.34 & -0.35 & 0.06 \\
\hline $\mathrm{VO}_{2}$ peak & $\mathrm{ml} / \mathrm{min} * \mathrm{~kg}$ & -0.38 & 0.03 & -0.45 & 0.03 & -0.39 & 0.02 \\
\hline $\mathrm{VO}_{2}$ peak predicted & $\%$ & -0.32 & 0.06 & -0.26 & 0.23 & -0.33 & 0.05 \\
\hline $\mathrm{VE} / \mathrm{VCO}_{2}$ Slope & & 0.05 & 0.76 & 0.12 & 0.58 & -0.16 & 0.42 \\
\hline Workload peak & Watt & -0.22 & 0.20 & -0.30 & 0.15 & -0.20 & 0.27 \\
\hline Workload peak predicted & $\%$ & -0.11 & 0.54 & -0.39 & 0.06 & -0.30 & 0.08 \\
\hline Oxygenpulse AT & $\mathrm{ml} /$ beat & -0.04 & 0.90 & -0.11 & 0.76 & -0.19 & 0.59 \\
\hline Oxygenpulse peak & $\mathrm{ml} /$ beat & -0.32 & 0.06 & -0.35 & 0.10 & -0.13 & 0.48 \\
\hline Oxygenpulse peak predicted & $\%$ & -0.19 & 0.27 & -0.23 & 0.28 & -0.24 & 0.17 \\
\hline $6 \mathrm{MWD}$ & $\mathrm{m}$ & 0.13 & 0.79 & 0.58 & 0.42 & 0.31 & 0.54 \\
\hline Heart rate recovery & beats $1 \mathrm{st} \min$ & -0.03 & 0.85 & 0.18 & 0.43 & 0.18 & 0.42 \\
\hline NTproBNP & $\mathrm{fmol} / \mathrm{ml}$ & 0.51 & 0.01 & & & 0.50 & 0.01 \\
\hline H-FABP & $\mathrm{pg} / \mathrm{ml}$ & & & 0.51 & 0.01 & 0.65 & 0.01 \\
\hline BigET1 & $\mathrm{fmol} / \mathrm{ml}$ & 0.65 & 0.01 & 0.50 & 0.01 & & \\
\hline
\end{tabular}

(b)

\begin{tabular}{|c|c|c|c|c|c|c|c|}
\hline \multicolumn{8}{|c|}{ Bivariate correlation of hemodynamics and biomarkers at baseline } \\
\hline Parameter & Unit & H-FABP & $\mathbf{p}$ & BNP & $\mathbf{p}$ & BigET1 & $\mathbf{p}$ \\
\hline MAP & $\mathrm{mmHg}$ & 0.12 & 0.49 & -0.10 & 0.61 & -0.09 & 0.66 \\
\hline MPAP & $\mathrm{mmHg}$ & -0.14 & 0.39 & -0.10 & 0.62 & 0.41 & 0.04 \\
\hline PCWP & $\mathrm{mmHg}$ & -0.01 & 0.96 & 0.01 & 0.97 & 0.27 & 0.15 \\
\hline TPG & $\mathrm{mmHg}$ & -0.13 & 0.45 & -0.10 & 0.64 & 0.25 & 0.12 \\
\hline RAP & $\mathrm{mmHg}$ & 0.13 & 0.44 & 0.48 & 0.02 & 0.73 & 0.001 \\
\hline RVEDP & $\mathrm{mmHg}$ & -0.14 & 0.47 & 0.20 & 0.44 & 0.53 & 0.001 \\
\hline $\mathrm{SaO}_{2}$ & $\%$ & -0.04 & 0.83 & -0.15 & 0.47 & -0.11 & 0.51 \\
\hline $\mathrm{SvO}_{2}$ & $\%$ & -0.29 & 0.07 & -0.64 & 0.00 & -0.53 & 0.002 \\
\hline Cardiac Index & $1 / \mathrm{min}^{*} \mathrm{~m}^{2}$ & -0.14 & 0.40 & -0.33 & 0.10 & -0.25 & 0.13 \\
\hline PVR & dyn $* \mathrm{~s}^{*} \mathrm{~cm}^{-5}$ & -0.07 & 0.70 & -0.13 & 0.54 & 0.14 & 0.40 \\
\hline SVR & dyn* ${ }^{*} \mathrm{~cm}^{-5}$ & 0.11 & 0.55 & 0.10 & 0.64 & 0.07 & 0.69 \\
\hline Resistance Index & & -0.26 & 0.12 & -0.17 & 0.42 & 0.53 & 0.004 \\
\hline
\end{tabular}



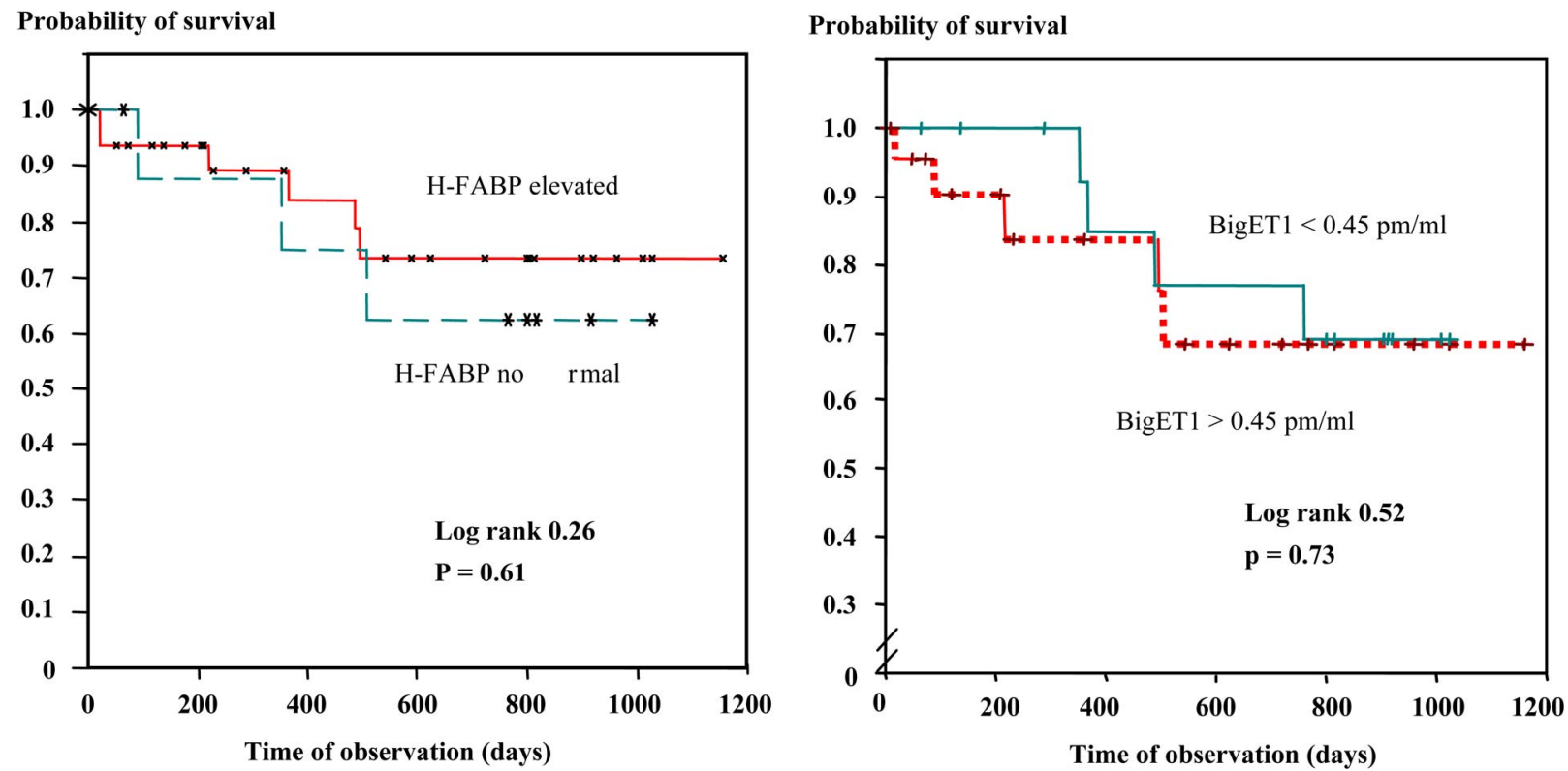

Figure 2. Kaplan Meier survival curves of patients with pre-capillary pulmonary hypertension in dependence of elevated levels of the three biomarkers H-FABP (upper graph) and Big-ET1 (lower graph). No differences in outcome could be seen in patients with elevated or normally ranged biomarker levels.

Table 4. Multivariate Hazard ratio for biomarkers in all PH patients. H-FABP and NT pro BNP revealed a HR beneath 1, whereas BigET1 possessed an increase HR of 1.88 for each increase of BigET1 by $1 \mathrm{fmol} / \mathrm{ml}$, but all HR's are not significant.

\begin{tabular}{|c|c|c|c|c|c|c|c|c|c|}
\hline \multirow{3}{*}{$\begin{array}{c}\text { Biomarker } \\
\text { H-FABP }\end{array}$} & \multirow{3}{*}{$\frac{\text { Unit }}{\mathrm{pg} / \mathrm{ml}}$} & \multicolumn{4}{|c|}{ All $\mathrm{PH}$ patients $(\mathrm{n}=41)$} & \multicolumn{4}{|c|}{ IPAH patients $(n=23)$} \\
\hline & & \multirow{2}{*}{$\begin{array}{c}\text { HR } \\
1\end{array}$} & \multicolumn{2}{|c|}{$95 \% \mathrm{CI}$} & \multirow{2}{*}{$\frac{\mathbf{p}}{0.44}$} & \multirow{2}{*}{$\begin{array}{c}\text { HR } \\
1\end{array}$} & \multicolumn{2}{|c|}{$95 \% \mathrm{CI}$} & \multirow{2}{*}{$\begin{array}{c}\mathbf{p} \\
0.14\end{array}$} \\
\hline & & & 0.99 & 1.01 & & & 0.99 & 1.01 & \\
\hline Nt pro BNP & $\mathrm{fmol} / \mathrm{ml}$ & 1.01 & 0.98 & 1.01 & 0.54 & 1 & 0.99 & 1.01 & 0.7 \\
\hline Big-ET1 & $\mathrm{fmol} / \mathrm{ml}$ & 1.88 & 0.89 & 3.97 & 0.09 & 5.01 & 0.65 & 38.71 & 0.12 \\
\hline
\end{tabular}

$\mathrm{cm}^{-5}$ was a strong hemodynamic parameter indicating a worse outcome (HR 25.66; $\mathrm{p}=0.01$ ) (Figure 3). In addition, an arterial oxygen saturation of haemoglobin above $90 \%$ revealed a HR of $0.07(\mathrm{p}=0.02)$ and a mixed venous $\mathrm{Hb}$ oxygen saturation more than $58 \%$ indicated a HR of $0.1(p=0.01)$ for deteriorated outcome by each declining percent of saturation. Neither, elevated MPAP, increased right or left ventricular and atrial filling pressures, nor the cardiac index were reliable values for the prognosis of $\mathrm{PH}$ patients. With regard to variables in the exercise test, respiratory efficacy, derived from the VE/ $\mathrm{VCO}_{2}$ slope with a cut off point of $60(\mathrm{HR} 8.24 ; \mathrm{p}=0.02)$ as well as the heart rate recovery (HRR), a marker of heart frequency decline in the early recovery period after the maximum of cycling exertion with a cut off point of $8 \mathrm{bpm}$ within the $1^{\text {st }}$ minute (HR 21.63; p < 0.01) were strongly associated with a poor prognosis. This result is independent of heart rate at rest (Figure 4). Surprisingly, neither $\mathrm{VO}_{2}$ peak $(>12.5 \mathrm{~m} / \mathrm{kg} / \mathrm{min}, \mathrm{HR} 0.4, \mathrm{p}=0.27)$ nor
6MWD (>320 m) were significantly associated with a better outcome in our mixed population (HR 0.93, p = $0.86)$. There was also no significant difference in 6MWD between the group treated with specific medication and those with newly diagnosed, yet untreated PH $(p=0.66)$. However this result is limited by the fact that only 28 patients underwent a $6 \mathrm{MWD}$. According to the results of the whole $\mathrm{PH}$ population, we detected that $\mathrm{SvO}_{2}>58 \%$ was independently associated with a better prognosis in patients with IPAH (HR 0.02, p = 0.03). In contrast, in patients with IPAH, the maximum of reached workload (>50 watt) (HR 0.02, p = 0.04) and peak oxygen consumption $(>12.5 \mathrm{ml} / \mathrm{kg} / \mathrm{min})(\mathrm{HR} 0.02, \mathrm{p}=0.06)$ reached statistical significance or tended to be associated with a better outcome. $\mathrm{VE} / \mathrm{VCO}_{2}$ slope of more than 60 (HR 2,64; $\mathrm{p}=0,4)$ as well as a HRR below $8 \mathrm{bpm} / 1^{\text {st }} \mathrm{min}(\mathrm{HR}$ $101,3 ; p=0,21)$ failed to predict a worse outcome in this IPAH subgroup (Table 5). Due to the only few events in this group and the consecutively wide spreading confi- 


\begin{tabular}{|c|c|c|c|c|}
\hline \multirow[b]{2}{*}{ MPAP > 50 mmHg } & \multirow{2}{*}{$\begin{array}{c}\text { HR } \\
0.59\end{array}$} & \multicolumn{2}{|c|}{$95 \%$ CI } & \multirow{2}{*}{$\begin{array}{c}\mathbf{p} \\
0.33\end{array}$} \\
\hline & & 0.16 & 2.55 & \\
\hline $\mathrm{RAP}>10 \mathrm{mmHg}$ & 0.90 & 0.13 & 3.34 & 0.65 \\
\hline RVEDP > $12 \mathrm{mmHg}$ & 1.64 & 0.23 & 11.62 & 0.62 \\
\hline PCWP > $8 \mathrm{mmHg}$ & 1.31 & 0.16 & 10.88 & 0.80 \\
\hline $\mathrm{CI}>2.0 \mathrm{l} / \mathrm{min}^{*} \mathrm{~m}^{2}$ & 0.27 & 0.05 & 1.40 & 0.12 \\
\hline PVR $>900$ dyn $*{ }^{*} \mathrm{~cm}^{-5}$ & 25.66 & 2.19 & 301.33 & 0.01 \\
\hline Resistance Index $>0.45$ & 2.88 & 0.31 & 26.39 & 0.35 \\
\hline $\mathrm{SvO}_{2}>58 \%$ & 0.10 & 0.02 & 0.60 & 0.01 \\
\hline $\mathrm{SaO}_{2}>90 \%$ & 0.07 & 0.01 & 0.63 & 0.02 \\
\hline
\end{tabular}

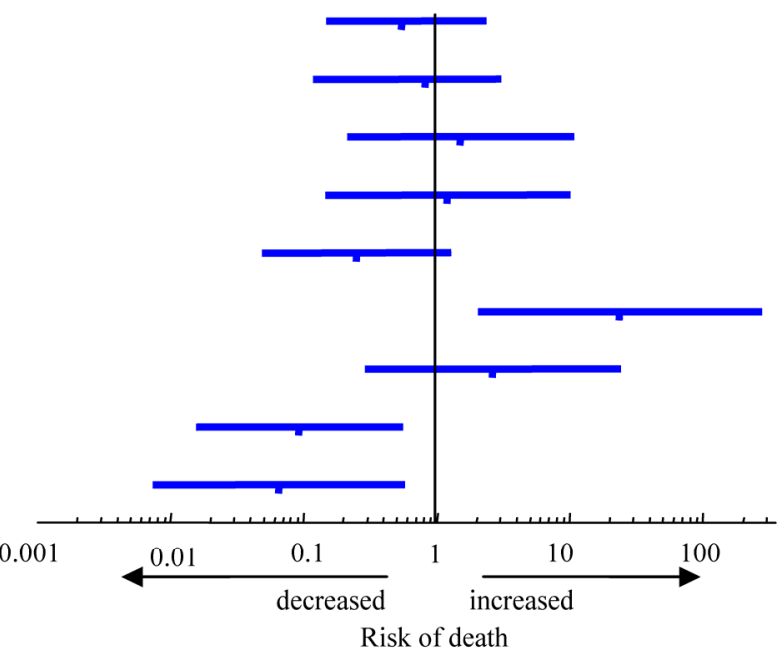

Figure 3. Multivariate Hazard ratio proportional test for hemodynamic factors predicting survival in PH patients. PVR $>900$ dyn $* \mathrm{~s}^{*} \mathrm{~cm}^{-5}$ is associated with an increased, low arterial and mixed venous $\mathrm{Hb}$ oxygen saturation with a decreased risk of death/HLtx. The levels of significant association are indicated.

\begin{tabular}{|c|c|c|c|c|}
\hline & HR & \multicolumn{2}{|c|}{$95 \%$ CI } & p \\
\hline $6 \mathrm{MWD}>320 \mathrm{~m}$ & 0.93 & 0.42 & 2.07 & 0.86 \\
\hline Workload peak $>60$ watts & 0.14 & 0.02 & 1.18 & 0.07 \\
\hline Workload peak pred. $>\mathbf{4 5 \%}$ & 0.18 & 0.02 & 1.38 & 0.1 \\
\hline $\mathrm{VO}_{2} \mathrm{AT}>10.5 \mathrm{mlO}_{2} / \mathrm{kg}^{*} \mathrm{~min}$ & 0.3 & 0.03 & 2.55 & 0.27 \\
\hline $\mathrm{VO}_{2}$ peak $>12.5 \mathrm{ml} / \mathrm{kg}^{*} \mathrm{~min}$ & 0.4 & 0.08 & 2.04 & 0.27 \\
\hline $\mathrm{VE} / \mathrm{CO}_{2}$ Slope at AT over 60 & 8.24 & 1.35 & 50.29 & 0.02 \\
\hline HRR $<8$ beats within 1 st min & 21.63 & 2.85 & 321.23 & 0.01 \\
\hline
\end{tabular}

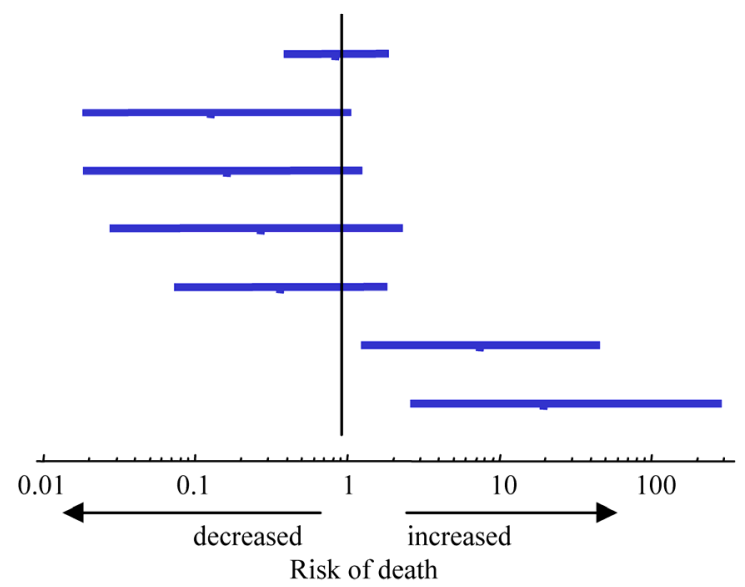

Figure 4. Multivariate Cox regression proportional analysis with Hazard ratios for exercise parameters predicting worse outcome in PH. A VE/ $\mathrm{VCO}_{2}$ Slope more than 60 contributes to an 8 fold, a HRR below than 8 beats within the first minute following peak exertion leads to a 22 fold increase in death/HLTx.

dence interval no statistical significance was reached.

\section{Discussion and Conclusions}

The prognostic assessment of pulmonary hypertension is difficult but important, particularly in the context of optimal timing for invasive procedures such as atrial septostomy or lung transplantation. Therefore, a simple, non-invasive, and repeatedly available method is desirable. Promising and indicative are studies measuring cardiac biomarkers in plasma such as plasma brain nat-
Table 5. Hazard ratio proportional test in the group of 23 IPAH patients. Displayed are only the 3 variables with the strongest interrelation to an adverse outcome. $\mathrm{SvO}_{2}$ and the maximum of workload in CPET show the strongest interrelation in IPAH patients.

\begin{tabular}{ccccc}
\hline Variable & HR & \multicolumn{2}{c}{$\mathbf{9 5 \%}$ CI } & p \\
\hline $\mathrm{SvO}_{2}>58 \%$ & 0.02 & 0.001 & 0.71 & 0.03 \\
Workload peak $>50$ watts & 0.02 & 0.001 & 0.73 & 0.04 \\
$\mathrm{VO}_{2}$ peak $>12,5 \mathrm{ml} / \mathrm{kg}^{*}$ min & 0.03 & 0.001 & 1.23 & 0.06 \\
\hline
\end{tabular}


riuretic peptide (BNP) or the N-terminal part of its prohormone $[23,24]$. The stimuli for increased secretion of BNP are ventricular wall stretch and volume overload [25]. Recently, newer myocardial biomarkers reflecting myocardial injury, but not stretch per se, such as troponin or H-FABP, have gained interest. In this study, we investigated the H-FABP to determine whether H-FABP is an indicator of disease severity and survival in patients with various forms of chronic pre-capillary $\mathrm{PH}$ within different stages of the disease and under different medical therapies. The salient finding of our study is that baseline serum levels of H-FABP are not able to predict an adverse outcome. In a midterm follow up period of about two years, baseline H-FABP concentrations were not different between patients with an adverse outcome compared to those with a favourable course. These data indicate the low predictive value of the biomarker. In addition, the probability of event free survival (HR 1.0, CI $0.99-1.01, \mathrm{p}=0.44$ ) was not predicted by increased levels of H-FABP. Similar results were obtained in the subgroup of 23 patients with IPAH. Only a weak correlation of H-FABP with the established prognostic parameter for CPET $\mathrm{VO}_{2}$ peak $(\mathrm{r}=-0.38, \mathrm{p}=0.03$ ) could be established. The H-FABP plasma levels failed to show any correlations with the other known prognostic hemodynamic markers of $\mathrm{PH}$ and right ventricular dysfunction (such as RAP, PVR, $\mathrm{SVO}_{2}, \mathrm{CO}$ ) [26] and exercise (6MWT, VE/ $/ \mathrm{VCO}_{2}$ ) parameters. Our findings are in contrast to the results of Lankeit et al. [28] who examined the prognostic value of H-FABP in 93 consecutive patients with the diagnosis of $\mathrm{PH}$, namely CTEPH. They found significantly higher H-FABP levels in patients with an adverse outcome, while a multivariate analysis revealed that H-FABP (HR 1.11, CI 1.02 - 1.22, p = 0.015 ) was an independent predictor of adverse outcome, along with RAP and pulmonary endarterectomy (PEA). Inter- estingly, in this selected study group baseline H-FABP levels were only weakly correlated with other prognostic relevant hemodynamic parameters $(\mathrm{CO}$, PCWP, RAP and 6MWD). The exact reasons for these apparent discrepancies to our results are unclear, especially in case of comparable median H-FABP levels between the different study groups. The main difference between the study groups consisted in the different aetiologies of $\mathrm{PH}$ and consecutive treatment options during the follow up. Particularly, the very selected entity (CTEPH) and the longer observation time in the study of Lankeit et al. [29] could be one explanation. In fact, 56\% of the CTEPH patients underwent surgical PEA and showed a drastic relieve of hemodynamic impact on their right atriums and ventricles. In addition, PEA was associated with a highly significant lower risk of an adverse outcome. In our unselected patient group with pulmonary hypertension of various aetiologies only 8 patients were diagnosed as CTEPH but without surgical accessibility of the thromboembolic lesions. During the observation period almost all patients received different medications for PH. In summary, these data indicated, that H-FABP even though representing an easily accessible biomarker, is not a reliable predictor for the outcome of these patients and thus cannot be used reliably to develop therapeutic strategies for individual patients with PH. In addition we did compare the hemodynamic and prognostic value of H-FABP with Big-ET and with the natriuretic peptide NT-Pro-BNP, which has already been shown to have prognostic relevance in patients with PH. Surprisingly, we observed moderate correlations between H-FABP and NT-Pro-BNP $(r=0.51, p=0.01)$ but higher correlations to Big-ET $(r=0.65, p=0.01)$. Big-ET and NT-Pro- BNP were moderately correlated to each another $(\mathrm{r}=0.5, \mathrm{p}=0.01)$, too. Like H-FABP, Big-ET and NT-Pro-BNP correlated weakly with $\mathrm{VO}_{2}$ peak $(r=-0.39, p=0.02$ and $r=-0.45, p=0.03$, respectively). But in contrast to H-FABP, NT-pro-BNP, and even more Big-ET showed weak to strong correlations to invasively measured he- modynamic parameters with known prognostic signifi- cance (NT-Pro-BNP: mRAP: $r$ $=48, \mathrm{p}=0.02$, mixed venous saturation $\left(\mathrm{SVO}_{2}\right) \mathrm{r}=$ $-0.64, \mathrm{p}<0.001$; (Big-ET: PAP: $\mathrm{r}=0.41, \mathrm{p}=0.04$; resistance index $\mathrm{r}=0.53, \mathrm{p}=0.004 ; \mathrm{SVO}_{2}: \mathrm{r}=-0.53, \mathrm{p}=$ 0.002; RVEDP: $\mathrm{r}=0.53, \mathrm{p}=0.001$ and mRAP: $\mathrm{r}=0.73$, $\mathrm{p}=0.001)$. Using the multi- variable Cox`s proportional hazard model NT-pro-BNP, comparable to H-FABP, had not emerged as an inde- pendent predictor of outcome in our study group of very unselected patients but also in the subgroup of IPAH patients. Only, increasing Big-ET levels, tended to be predictive for an adverse outcome in the whole group (HR 1.88, CI $0.89-3.97, \mathrm{p}=0.09$ ) and in IPAH (HR 5.01, CI $0.65-38.7, \mathrm{p}=0.12$ ). Accordingly, Big-ET, compared with H-FABP and NT-pro-BNP, showed the highest correlations with different prognostic relevant hemodynamic parameters of pulmonary hypertension and right ventricular dysfunction. In contrast to the biomarker H-FABP, hemodynamic and exercise test parameters were proved to have at least a good correlation with survival. In the multivariate Hazard ratio proportional test, the hemodynamic parameters PVR, $\mathrm{SVO}_{2}$ und $\mathrm{SAO}_{2}$ and the exercise parameters $\mathrm{VE} / \mathrm{VECO}_{2}$ slope at AT and, sur- prisingly, the heart rate recovery (HRR) were independ- ently associated with an adverse vs. a favourable out- come. Most interestingly in this context is the non-inva- sive derived CPET parameter HRR $(<8$ beats within the first minute) with its very powerful predictive value (HR 21.63, CI 2.85 - 321.21, p = 0.01) for adverse outcome in our patient group. The rise in heart rate during exercise is considered to be due to the com- 
bination of parasympathetic withdrawal and sympathetic activation [27]. The fall in heart rate immediately after exercise is considered to be a function of reactivation of the parasympathetic nervous system [28]. Increased vagal activity has been associated with a reduction in the risk of death [29]. In contrast, a slow rate of heart rate recovery after exercise testing is a powerful and independent predictor of overall mortality. This easily available marker is independent from workload, the presence or absence of myocardial perfusions defects, and changes in heart rate during exercise [30]. In patients with left heart failure, delayed heart rate recovery is a significant predictor of both sudden cardiac death and mortality due to pump failure [31]. With regard to pulmonary diseases, different observations are consistent with the existence of an important imbalance of autonomic dysfunction in patients with various grades of lung disease. For example, Seshadri et al. [32] demonstrated that in COPD patients either obstructive or restrictive abnormalities found on spirometry are associated with abnormal heart rate recovery. With re- gard to pulmonary hypertension, Velez-Roa et al. [33] reported that the activity of the sympathetic nervous sys- tem, as assessed by peroneal nerve microneuropathy, is markedly increased in patients with pulmonary arterial hypertension. This sympathetic overactivity appears to be related to right atrial distention and decreased cardiac output. Both may be improved by atrial septostomy, a live saving intervention for patients with severe PAH, to bridge for lung transplantation. In fact, Ciarka et al. [34] showed that atrial septostomy in PAH patients decreases sympathetic nerve hyperactivity, mostly related to de- creased right atrial distension. The specific role of an additionally modulated parasympathetic reactivation, reflected by a diminished HRR, was not examined in these studies. Recently, Swigris et al. [35] could show that in patients with idiopathic pulmonary fibrosis and pulmonary hypertension an abnormal heart rate recovery after 6MWT appeared to be the most potent predictor of mortality (HR 5,2). The findings of the present study, however, demonstrated that a diminished HRR ( $<8$ beat within the first minute) was able to indicate an adverse outcome in patients with pre-capillary pulmonary hyper-tension of different causes. Thus, the present study strongly supports the notion that in patients with pre-capillary pulmonary hypertension the imbalance of the autonomic nerve system is of utmost importance for prognosis. Future studies with larger numbers of patients and potentially longer follow up have to define the exact role of such an autonomic dysfunction in the pathophysiology and prognosis of pulmonary arterial hypertension.

The main limitations of the present study are the population size of only 41 patients. This is due to the low prevalence of this disease. In an attempt to evaluate the different prognostic parameters in patient groups with distinct aetiologies of pre-capillary pulmonary hypertension, we calculated the results at first for all patients, followed by a calculation for the IPAH patients only. But, the even smaller number of patients of the latter group (IPAH, $\mathrm{n}=23$ ) with only 6 major events in the follow up period does not allow any final conclusions and may only be considered as pilot data. One of the best evaluated prognostic predictors in patients with IPAH and other causes of pre-capillary hypertension is the 6MWD [36]. In our study only 28 patients underwent the 6MWD test. However, in the present study an independent prognostic value of this exercise parameter could not be achieved, neither in IPAH patients nor in the total, unselected PH hypertension group. Again, this may be due to the different severities and stages of the disease. Further studies have to address this valid point.

In conclusions, the present study indicates that $\mathrm{H}$ FABP is neither a reliable parameter of disease severity nor a novel predictor of mid and long term outcome in patients with various forms of pre-capillary pulmonary hypertension. Also, other biomarkers such as NT-ProBNP and Big-ET did not appear to be useful tools for outcome stratification in this patient group. They reflect the disease severity better, because of their moderate to high correlation to different hemodynamic and exercise parameters. Still, they did not prove to be independent predictors of event free survival. More promising diagnostic tools with prognostic relevance for such typically unselected patients could be the well known and established exercise parameters of an increased slope of $\mathrm{VE} / \mathrm{VCO}_{2}$, but also a delayed HRR, the latter indicative for a diminished vagal activity. Both are noninvasive and easily measurable parameters. Especially, the quite powerful and easily accessible predictive value of heart rate recovery (HRR) may provide the rationale for new studies defining the temporal relation of autonomic nervous system distortion to right heart failure with bad prognosis in pulmonary arterial hypertension.

\section{Acknowledgements}

H.S. thanks $\mathrm{MH}$ who participated in the design of the study and helped to perform right heart catheterization and CPET, DS who participated in study coordination, data acquisition and performing statistical analysis. Sincere thanks are given to PB carried out the immunoassays, to GH, RCBD and RHS helped to draft the manuscript and revised it critically and to AS who conceived of the study, and participated in creating design, participated in the sequence alignment, drafted the manuscript, performed right heart catheterization and gave final ap- 
proval of the version to be published. All authors read and approved the final manuscript.

\section{References}

[1] W. Klepetko, E. Mayer, J. Sandoval, E. P. Trulock, J. L. Vachiery, P. Dartevelle, J. Pepke-Zaba, S. W. Jamieson, I. Lang and P. Corris, "Interventional and Surgical Modalities of Treatment for Pulmonary Arterial Hypertension," Journal of the American College of Cardiology, Vol. 43, No. 12, 2004, pp. 73S-80S.

doi:10.1016/j.jacc.2004.02.039

[2] R. J. Barst, M. McGoon, A. Torbicki, O. Sitbon, M. J. Krowka, H. Olschewski and S. Gaine, "Diagnosis and Differential Assessment of Pulmonary Arterial Hypertension," Journal of the American College of Cardiology, Vol. 43, No. 12, 2004, pp. 40S-47S. doi:10.1016/j.jacc.2004.02.032

[3] V. V. McLaughlin, K. W. Presberg, R. L. Doyle, S. H. Abman, D. C. McCrory, T. Fortin and G. Ahearn, "Prognosis of Pulmonary Arterial Hypertension: ACCP Evidence-Based Clinical Practice Guidelines," Chest, Vol. 126, No. 1, 2004, pp. 78S-92S. doi:10.1378/chest.126.1_suppl.78S

[4] A. Torbicki, M. Kurzyna, P. Kuca, A. Fijalkowska, J. Sikora, M. Florczyk, P. Pruszczyk, J. Burakowski and L. Wawrzynska, "Detectable Serum Cardiac Troponin T as a Marker of Poor Prognosis among Patients with Chronic Precapillary Pulmonary Hypertension," Circulation, Vol. 108, No. 7, 2003, pp. 844-848. doi:10.1161/01.CIR.0000084544.54513.E2

[5] S. B. Eysmann, H. I. Palevsky, N. Reichek, K. Hackney, P. S. Douglas, "Two-Dimensional and Doppler- Echocardiographic and Cardiac Catheterization Correlates of Survival in Primary Pulmonary Hypertension," Circulation, Vol. 80, 1989, pp. 353-360. doi:10.1161/01.CIR.80.2.353

[6] R. J. Raymond, A. L. Hinderliter, P. W. Willis, et al., "Echocardiographic Predictors of Adverse Outcomes in Primary Pulmonary Hypertension," Journal of the American College of Cardiology, Vol. 39, No. 7, 2002, pp. 1214-1219. doi:10.1016/S0735-1097(02)01744-8

[7] N. Galie, A. L. Hinderliter, A. Torbicki, et al., "Effects of the Oral Endothelin-Receptor Antagonist Bosentan on Echocardiographic and Doppler Measures in Patients with Pulmonary Arterial Hypertension," Journal of the American College of Cardiology, Vol. 41, No. 8, 2003, pp. 1380-1386. doi:10.1016/S0735-1097(03)00121-9

[8] S. M. Kawut, E. M. Horn, K. K. Berekashvili, et al., "New Predictors of Outcome in Idiopathic Pulmonary Arterial Hypertension," The American Journal of Cardiology, Vol. 95, No. 2, 2005, pp. 199-203. doi:10.1016/j.amjcard.2004.09.006

[9] N. Nagaya, T. Nishikimi, M. Uematsu, et al., "Plasma Brain Natriuretic Peptide as a Prognostic Indicator in Patients with Primary Pulmonary Hypertension," Circulation, Vol. 102, 2000, pp. 865-870.

[10] H. H. Leuchte, N. M. El, J. C. Tuerpe, et al., "N-terminal
Pro-brain Natriuretic Peptide and Renal Insufficiency as Predictors of Mortality in Pulmonary Hypertension," Chest, Vol. 131, No. 2, 2007, pp. 402-409. doi:10.1378/chest.06-1758

[11] H. H. Leuchte, M. Holzapfel, R. A. Baumgartner, et al., "Clinical Significance of Brain Natriuretic Peptide in Primary Pulmonary Hypertension," Journal of the American College of Cardiology, Vol. 43, No. 5, 2004, pp. 764-770. doi:10.1016/j.jacc.2003.09.051

[12] N. Nagaya, T. Nishikimi, Y. Okano, et al., "Plasma Brain Natriuretic Peptide Levels Increase in Proportion to the Extent of Right Ventricular Dysfunction in Pulmonary Hypertension," Journal of the American College of Cardiology, Vol. 31, No. 1, 1998, pp. 202-208. doi:10.1016/S0735-1097(97)00452-X

[13] N. Nagaya, T. Nishikimi, M. Uematsu, et al., "Plasma Brain Natriuretic Peptide as a Prognostic Indicator in Patients with Primary Pulmonary Hypertension," Circulation, Vol. 102, 2000, pp. 865-870.

[14] A. Fijalkowska, M. Kurzyna, A. Torbicki, et al., "N-Terminal Brain Natriuretic Peptide as a Prognostic Parameter in Patients with Pulmonary Hypertension," Chest, Vol. 129, No. 5, 2006, pp. 1313-1321. doi:10.1378/chest.129.5.1313

[15] M. M. Pelsers, W. T. Hermens and J. F. Glatz, "Fatty Acid-Binding Proteins as Plasma Markers of Tissue Injury," Clinica Chimica Acta, Vol. 352, No. 1-2, 2005, pp. 15-35. doi:10.1016/j.cccn.2004.09.001

[16] H. A. Alhadi and K. A. Fox, "Do We Need Additional Markers of Myocyte Necrosis: The Potential Value of Heart Fatty-acid-binding Protein," QJM, Vol. 97, No. 4, 2004, pp. 187-198. doi:10.1093/qjmed/hch037

[17] M. M. Pelsers, W. T. Hermens, J. F. Glatz, "Fatty Acid-Binding Proteins as Plasma Markers of Tissue Injury," Clinica Chimica Acta, Vol. 352, No. 1-2, 2005, pp. 15-35. doi:10.1016/j.ccen.2004.09.001

[18] M. Puls, C. Dellas, M. Lankeit, et al., "Heart-Type Fatty Acid-Binding Protein Permits Early Risk Stratification of Pulmonary Embolism," European Heart Journal, Vol. 28, No. 2, 2007, pp. 224-229. doi:10.1093/eurheartj/ehl405

[19] A. Kaczynska, M. M. Pelsers, A. Bochowicz, et al., "Plasma Heart-Type Fatty Acid Binding Protein is Superior to Troponin and Myoglobin for Rapid Risk Stratification in Acute Pulmonary Embolism," Clinica Chimica Acta, Vol. 371, No. 1-2, 2006, pp. 117-123.

doi:10.1016/j.cca.2006.02.032

[20] M. Lankeit, C. Dellas, A. Panzenbock, et al., "HeartType Fatty Acid-Binding Protein for Risk Assessment of Chronic Thromboembolic Pulmonary Hypertension," European Respiratory Journal, Vol. 31, No. 5, 2008, pp. 10241029. doi:10.1183/09031936.00100407

[21] J. L. Snow and S. M. Kawut, "Surrogate End Points in Pulmonary Arterial Hypertension: Assessing the Response to Therapy," Clinics in Chest Medicine, Vol. 28, No. 1, 2007, pp. 75-89. doi:10.1016/j.ccm.2006.11.005

[22] ATS Committee on Proficiency Standards for Clinical Pulmonary Function Laboratories, "ATS Statement: Guidelines for the Six-Minute Walk Test," American Journal of 
Respiratory and Critical Care Medicine, Vol. 166, No. 1, 2002, pp. 111-117.

[23] N. Nagaya, T. Nishikimi, M. Uematsu, et al., "Plasma Brain Natriuretic Peptide as a Prognostic Indicator in Patients with Primary Pulmonary Hypertension," Circulation, Vol. 102, 2000, pp. 865-870.

[24] H. H. Leuchte, N. M. El, J. C. Tuerpe, et al., "N-terminal Pro-brain Natriuretic Peptide and Renal Insufficiency as Predictors of Mortality in Pulmonary Hypertension," Chest, Vol. 131, No. 2, 2007, pp. 402-409. doi: $10.1378 /$ chest.06-1758

[25] J. A. de Lemos, D. K. McGuire and M. H. Drazner, "B-type Natriuretic Peptide in Cardiovascular Disease," Lancet, Vol. 362, No. 9380, 2003, pp. 316-322. doi:10.1016/S0140-6736(03)13976-1

[26] S. Rosenkranz, "Pulmonary Hypertension: Current Diagnosis and Treatment," Clinical Research in Cardiology, Vol. 96, No. 8, 2007, pp. 527-541. doi:10.1007/s00392-007-0526-8

[27] Y. Arai, J. P. Saul, P. Albrecht, et al., "Modulation of Cardiac Autonomic Activity during and Immediately after Exercise," American Journal of Physiology, Vol. 256, No. 1, 1989, pp. H132-H141.

[28] K. Imai, H. Sato, M. Hori, et al., "Vagally Mediated Heart Rate Recovery after Exercise is Accelerated in Athletes but Blunted in Patients with Chronic Heart Failure," Journal of the American College of Cardiology, Vol. 24, No. 6, 1994, pp. 1529-1535. doi:10.1016/0735-1097(94)90150-3

[29] P. J. Schwartz, M. T. La Rovere and E. Vanoli, “Autonomic Nervous System and Sudden Cardiac Death. Experimental Basis and Clinical Observations for PostMyocardial Infarction Risk Stratification," Circulation,
Vol. 85, 1992, pp. I77-I91.

[30] C. R. Cole, E. H. Blackstone, F. J. Pashkow, et al., "Heart-Rate Recovery Immediately after Exercise as a Predictor of Mortality," The New England Journal of Medicine, Vol. 341, 1999, pp. 1351-1357. doi:10.1056/NEJM199910283411804

[31] M. Guazzi, J. Myers, M. A. Peberdy, et al., "Heart Rate Recovery Predicts Sudden Cardiac Death in Heart Failure," International Journal of Cardiology, Vol. 144, No. 1, 2009, pp. 121-123. doi:10.1016/j.ijcard.2008.12.149

[32] N. Seshadri, T. R. Gildea, K. McCarthy, et al., "Association of an Abnormal Exercise Heart Rate Recovery with Pulmonary Function Abnormalities," Chest, Vol. 125, No. 4, 2004, pp. 1286-1291. doi:10.1378/chest.125.4.1286

[33] S. Velez-Roa, A. Ciarka, B. Najem, et al., "Increased Sympathetic Nerve Activity in Pulmonary Artery Hypertension," Circulation, Vol. 110, 2004, pp. 1308-1312. doi:10.1161/01.CIR.0000140724.90898.D3

[34] A. Ciarka, J. L. Vachiery, A. Houssiere, et al., "Atrial Septostomy Decreases Sympathetic Overactivity in Pulmonary Arterial Hypertension," Chest, Vol. 131, No. 6, 2007, pp. 1831-1837. doi:10.1378/chest.06-2903

[35] J. J. Swigris, J. Swick, F. S. Wamboldt, et al., "Heart Rate Recovery after 6-Minute Walk Test Predicts Survival in Patients with Idiopathic Pulmonary Fibrosis," Chest, Vol. 136, No. 3, 2009, pp. 841-848. doi:10.1378/chest.09-0211

[36] S. Miyamoto, N. Nagaya, T. Satoh, et al., "Clinical Correlates and Prognostic Significance of Six-Minute Walk Test in Patients with Primary Pulmonary Hypertension: Comparison with Cardiopulmonary Exercise Testing," American Journal of Respiratory and Critical Care Medicine, Vol. 161, No. 2, 2000, pp. 487-492. 